\title{
Arquitetura estratigráfica dos depósitos fluviais albianos da base da Formação São Mateus no norte da Bacia do Espírito Santo
}

\author{
Renata dos Santos ALVARENGA, Claiton Marlon dos Santos SCHERER, Juliano KUCHLE \\ \& Luis Fernando DE ROS
}

Instituto de Geociências, Universidade Federal do Rio Grande do Sul. Av. Bento Gonçalves, 9.500, CEP 91.540-000, Porto Alegre, RS, Brasil

(renatalvarenga@yahoo.com.br, claiton.scherer@ufrgs.br, juliano.kuchle@ufrgs.br, Ifderos@inf.ufrgs.br).

\begin{abstract}
Resumo. Os depósitos aluviais da Formação São Mateus (Albiano) são produtores subordinados na Bacia do Espírito Santo. Embora os depósitos albianos representem importante potencial de reservatório em extensas áreas da bacia, existem poucos estudos detalhando a estratigrafia da seção clástica desse intervalo. Este trabalho apresenta um estudo estratigráfico de alta resolução da seção basal do Albiano, que é constituído predominantemente por depósitos aluviais. Esses depósitos apresentam grandes dificuldades para a correlação estratigráfica. Portanto, a estratégia de correlação foi subdividir a sucessão aluvial em ciclos estratigráficos. Esse método é baseado na variação da razão entre as taxas de criação de espaço de acomodação e suprimento sedimentar (A:S), que controla diretamente o grau de amalgamação dos corpos arenosos de canais fluviais. Com essa abordagem, foram definidos seis ciclos, compostos internamente por tratos de sistema de alta e baixa acomodação. Esses ciclos refletem a estruturação do arranjo da amalgamação dos canais fluviais em relação aos depósitos externos aos canais, contribuindo para o entendimento da dinâmica deposicional no intervalo clástico basal do Albiano clástico na Bacia do Espírito Santo.
\end{abstract}

Palavras-chave. Bacia do Espírito Santo, fluvial, Ciclos A:S

\begin{abstract}
StRATIGRAPHIC ARCHITECTURE OF THE ALBIAN FLUVIAL DEPOSITS OF THE SÃO MATEUS FORMATION BASE, NORTH OF THE ESPíRITO SANTO BASIN. Alluvial deposits of the São Mateus Formation (Albian) are subordinate producers in the Espírito Santo Basin. Although the Albian deposits represent important reservoir potential in extensive areas of the basin, there are few studies detailing the stratigraphy of the clastic section of this interval. This paper presents a high-resolution stratigraphic study of the basal Albian section, which consists predominantly of alluvial deposits. These deposits present large difficulties for the stratigraphic correlation. Therefore, the correlation strategy was to subdivide the alluvial succession into stratigraphic cycles. This method is based on the variation in the ratio between the rates of creation of accommodation space and sediment supply (A:S), which directly controls the degree of amalgamation of sandstone bodies in the fluvial channels. With this approach, six cycles were defined, internally composed of high and low accommodation system tracts. These cycles reflect the amalgamation structuring of the fluvial channels relative to the deposits external to the channels, contributing to the understanding of the depositional dynamics in the basal clastic Albian interval in the Espírito Santo Basin.
\end{abstract}

Keywords. Espírito Santo Basin, fluvial, A:S Cycles 


\section{Introdução}

Os depósitos da Formação São Mateus do Grupo Barra Nova apresentam interesse econômico pois são produtores secundários em diversos campos de petróleo terrestres na Bacia do Espírito Santo. O aumento da produção em campos já bem desenvolvidos passa necessariamenteporumavançadoconhecimento dos litotipos e geometrias reservatórios, suas barreiras de fluxo e conectividades (Galloway \& Hobday, 1996). Desta forma, a caracterização de fácies, associações defácies esuapredição dentro de um arcabouço da estratigrafia de sequencias fornece um conhecimento preditivo fundamental para a definição do arranjo geométrico das zonas produtoras de um reservatório. Desta forma, o presente artigo propõe um modelo de arquitetura deposicional e evolução estratigráfica para os depósitos albianos da Formação São Mateus da Bacia do espírito Santo, objetivando uma maior compreensão da disposição geométrica e predição de tendências a fim de fornecer subsídios para uma análise dos reservatórios em nível avançado. Também apresenta contribuição para modelos estratigráficos sequenciais em unidades exclusivamente fluviais.

A estratigrafia de sequências tem como base a identificação e delimitação de unidades geneticamente relacionadas limitadas no topo e na base por superfícies regionais (Catuneanu, 2006; Catuneanu et al., 2009). Os conceitos básicos da estratigrafia de sequências (Vail et al., 1977; Posamentier et al., 1988; Van Wagoner et al., 1988, 1990) foram amplamente aplicados em depósitos costeiros e plataformais, onde a acumulação e preservação dos sedimentos respondem a razão entre a taxa de criação e/ ou destruição de acomodação (A) e a taxa de influxo sedimentar (S). A razão A/S controla os padrões de empilhamento e, por consequência, o desenvolvimento dos tratos de sistemas deposicionais e de suas superfícies limítrofes. Entretanto, diferentes autores têm mostrado a dificuldade de se utilizar a terminologia dos tratos de sistemas e das superfícies limítrofes tradicionais da estratigrafia de sequências em sucessões aluviais (e.g. Currie, 1997; Aitken \& Flint, 1995; Dalrymple et al., 1998; Martinsen et al., 1999; Catuneanu et al., 2009). Como exemplo pode-se citar as superfícies transgressivas e de máxima inundação que têm as suas gêneses vinculadas a processos marinhos, dificultando de forma extrema o seu reconhecimento em sucessões eminentemente fluviais. Mesmo a determinação dos limites de sequências, que correspondem nas porções proximais a superfícies de erosão e exposição subaérea e, portanto, passíveis de ser encontrado em sucessões aluviais, não é uma tarefa fácil, uma vez que é extremamente difícil a discriminação entre superfícies erosivas de extensão regional gerada por variação do nível de base (processos alogênicos), daquelas vinculadas a migração e avulsão de canais, cujo preenchimento pode conter diversas outras superfícies deposicionais de menor hierarquia (fatores autogênicos), principalmente em contextos onde os estudos estão baseados somente em dados de poços e de perfilagem geofísica.

Diante destas dificuldades, uma estratégia de correlação é a subdivisão das sucessões aluviais em ciclos estratigráficos que respondam as variações do nível de base (perfil de equilíbrio) e que possam ser reconhecidos através da análise vertical de dados de poços. As variações na razão entre as taxas de criação de acomodação: suprimento sedimentar (A:S) controla o grau de amalgamação dos corpos arenosos de canais fluviais (e.g. Ramón \& Cross, 1997; Martinsen et al., 1999; Catuneanu \& Sweet, 1999; Catuneanu \& Elango, 2001). Intervalos caracterizados por corpos arenosos de canais fluviais, lateral e verticalmente amalgamados, com ausência ou raras ocorrências de depósitos externos aos canais, indicam um contexto de baixa razão A:S definindo um trato de sistema de baixa acomodação (Ramón \& Cross, 1997; Martinsen et al., 1999; Catuneanu et al., 2009). Por outro lado, sucessões aluviais com corpos arenosos isolados e/ou intercalados com abundantes depósitos externos aos canais fluviais indicam que a acumulação fluvial ocorreu em um contexto de alta razão A:S. Esta mudança unidirecional no grau de amalgamação dos corpos arenosos pode ser interpretada partir dados unidimensionais de poços e testemunhos, facilitando a elaboração 
do arcabouço estratigráfico de alta resolução de sucessões aluviais, bem como permitindo a predição da arquitetura dos reservatórios em subsuperfície.

O presente trabalho tem por objetivo a definição de um arcabouço estratigráfico de alta resolução para os depósitos aluviais da Formação São Mateus, Albiano da Bacia do Espírito Santo, tendo como base a definição de ciclos de aumento e diminuição da taxa A/S a partir do grau de amalgamação dos corpos arenosos de canais fluviais.

\section{2 Área, matérias e métodos}

\subsection{Contexto geológico}

A Bacia do Espírito Santo faz parte do conjunto de bacias de margem passiva da Margem Leste Brasileira e a sua evolução tectônica, se assemelha com as outras bacias marginais, sendo estreitamente ligadas à fragmentação do megacontinente Gondwana, com a separação da África e da América do Sul. As bacias da Margem Leste Brasileira possuem duas fases principais: a) fase rifte, onde são observados os processos de deformação envolvendo o embasamento, que permanecem até o momento do rompimento da litosfera, associado a um evento mecânico distensivo; e b) fase de subsidência térmica, quando os processos de deformação se caracterizam por reativar as falhas do embasamento e desenvolver novos falhamentos rasos, relacionados a uma margem continental (Chang et al., 1988).

A fase rifte é responsável pela geração das falhas normais escalonadas atingindo os sedimentos neocomianos até a base dos evaporitos de idade Alagoas Superior. Estas falhas são genericamente paralelas ao eixo principal de abertura da calha rifte. A maior parte destas estruturas possui mergulho em alto ângulo para leste, mas ocorrem também falhas antitéticas com mergulho para oeste (Costa, 1988). Essas falhas normais sintéticas e antitéticas formam um típico sistema horstgraben, e reproduzem, de um modo geral, o estilo estrutural do embasamento (Costa, 1988). Ocorre o predomínio de um sistema de direção NNE, interceptado por outro sistema de direção NW, o sistema N-NE é o principal responsável pela estruturação da bacia, o qual se desenvolveu em resposta a uma extensão aproximadamente E-W a NW-SE durante a fase de deriva continental. O sistema de falhas NE é deslocado no sentido anti-horário pelo sistema de falhas NW, conforme é sugerido pelo deslocamento dos sedimentos de idade Jiquiá e dos evaporitos (Costa, 1988), sendo que o sistema NW parece ter atuado durante o Alagoas Superior.

A fase de subsidência térmica ocorreu a partir do Alagoas Superior, quando os continentes sul-americano e africano se separam, com o efetivo rompimento da litosfera e criação do centro de espalhamento onde se inicia a formação da crosta oceânica. A dinâmica da sedimentação desta fase, que perdura até hoje, está intimamente associada aos processos de fluxo da sequência de evaporitos depositadas ao final da fase rifte. Esta movimentação (halocinese) foi provocada tanto devido ao basculamento da bacia para leste, quanto pela própria carga litostática diferencial, maior nas regiões próximas a costa e menor nas regiões distais da bacia (Costa, 1988). Durante a fase marinha ocorreram manifestações vulcânicas bastante intensas (Banco de Abrolhos). Esta feição, teve sua instalação mais próxima à linha de costa na porção setentrional da Bacia, bloqueando o deslizamento gravitacional com mais efetividade nesta porção, tendendo a estabilização do sal por volta do Meso-Eoceno. Ao contrário, no sul devido o Banco de Abrolhos estar mais afastado, o deslizamento do sal perdurou por mais tempo (Guerra, 1989).

O preenchimento sedimentar da Bacia do Espírito Santocompreendeuma série de depósitos que vão desde idade eocretácica à quaternária, com espessura total estimada superior a 11.000 m nos depocentros. A seção sedimentar da bacia compreende três supersequências deposicionais: Supersequência Rifte, Supersequência Pós-Rifte e Supersequência Drifte (França et al., 2007) (Fig. 1). A Supersequência Rifte envolve depósitos do Valangiano ao Aptiano Inferior correspondendo a Formação Cabiúnas e Formação Cricaré. O ambiente lacustre predomina, mas também há contribuição de depósitos fluviais e aluviais, nas 
bordas dos falhamentos e depósitos de coquinas e outros carbonatos nos altos estruturais internos e depósitos de vulcânicas. A Supersequência Pós-Rifte envolve os depósitos do Andar Alagoas Inferior ao Superior, correspondendo à Formação Mariricu - membros Mucuri e Itaúnas. Os sedimentos do Membro Mucuri envolvem depósitos de leques aluviais, fluviais e no topo um sistema de lagunas lamosas que evolui para o ambiente evaporítico do tipo sabka. A deposição do Membro Itaúnas ocorreu sob condições de uma bacia restrita e com alta evaporação acarretando grandes depósitos de anidrita e halita em uma superfície peneplanizada durante a fase de quiescência tectônica (França et al., 2007). A Supersequência Drifte abrange os depósitos do Grupo Barra Nova (Albiano) aos depósitos atuais que na parte emersa da bacia correspondem aos depósitos de sedimentos de planícies próximos à foz dos rios São Mateus e Rio Doce e aos cordões litorâneos ao longo da costa, (França et al., 2007). Esta Supersequência se refere a estágios iniciais com características de mar epicontinental passando para marinho. O Grupo

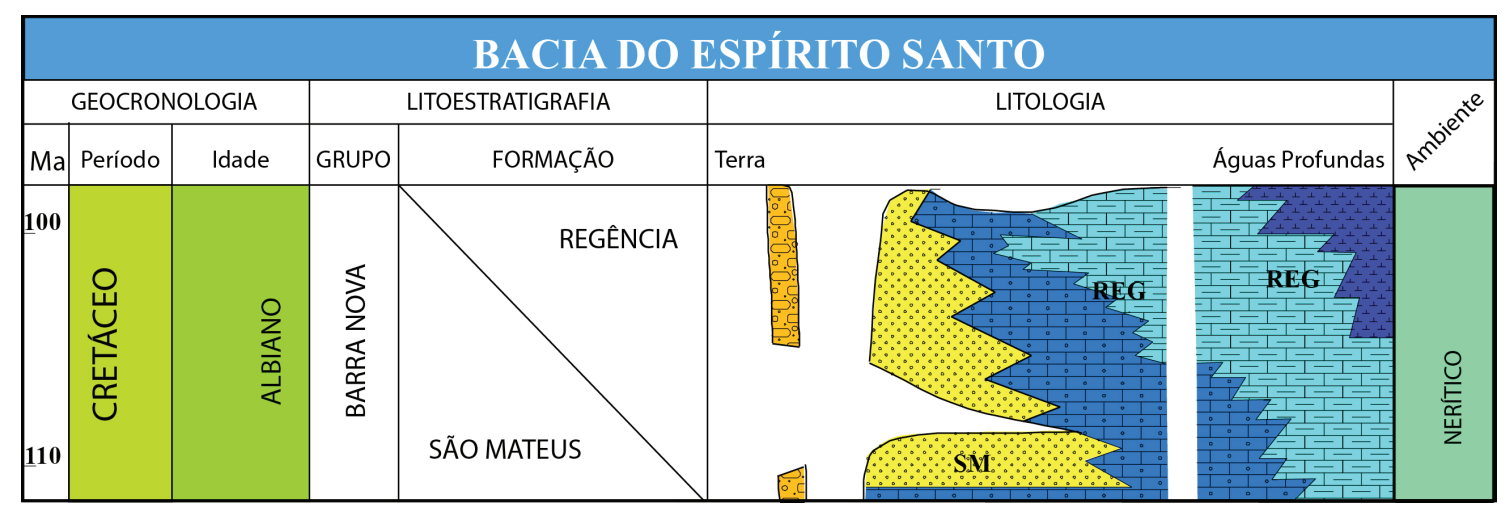

Figura 1. Coluna estratigráfica para os depósitos cretáceos da Bacia do Espírito Santo (Extraído e modificado de Vieira et al., 1994). SM: Formação São Mateus, REG: Formação Regência.

Figure 1. Stratigraphic Column for the Cretaceous deposits of the Espírito Santo Basin (Extracted and modified from Vieira et al., 1994). SM: São Mateus Formation; REG: Regência Formation.

Barra Nova, objetivo deste estudo, é caracterizada por espessos pacotes clásticos (Formação São Mateus) e carbonáticos (Formação Regência), depositados durante o Albiano. A Formação São Mateus é composta por depósitos de leques aluviais e costeiros, em ambiente marinho. 0 contato basal desta unidade é concordante com a Formação Mariricu e o contato superior é gradacional ou interdigitado lateralmente com a Formação Regência ou discordante com o Grupo Espírito Santo (Vieira et al., 1994).

\subsection{Localização}

A Bacia do Espírito Santo está situada na margem continental leste brasileira entre os paralelos $18^{\circ} 20^{\prime} \mathrm{S}$ e $21^{\circ} 00^{\prime} \mathrm{S}$, sendo delimitada a norte com a Bacia de Mucuri e a sul com a Bacia de Campos, através do Alto de Vitória (Fig. 2).
Possui uma área explorável de $41.000 \mathrm{Km}^{2}$, dos quais $3.000 \mathrm{Km}^{2}$ referem-se à parte emersa. A área do presente estudo abrange parte norte da Plataforma de São Mateus, porção emersa da bacia.

\subsection{Dados utilizados e metodologia}

Este trabalho tem como metodologia a integração das áreas de sedimentologia, estratigrafia e estrutural, as quais apresentam técnicas distintas, mas complementares dentro do objetivo proposto.

O desenvolvimento deste estudo foi realizado com base em dados de subsuperfície (poços testemunhados e perfis elétricos), visto que os afloramentos existentes na bacia são essencialmente compostos pelas formações Barreiras e Rio Doce. O conjunto de dados 


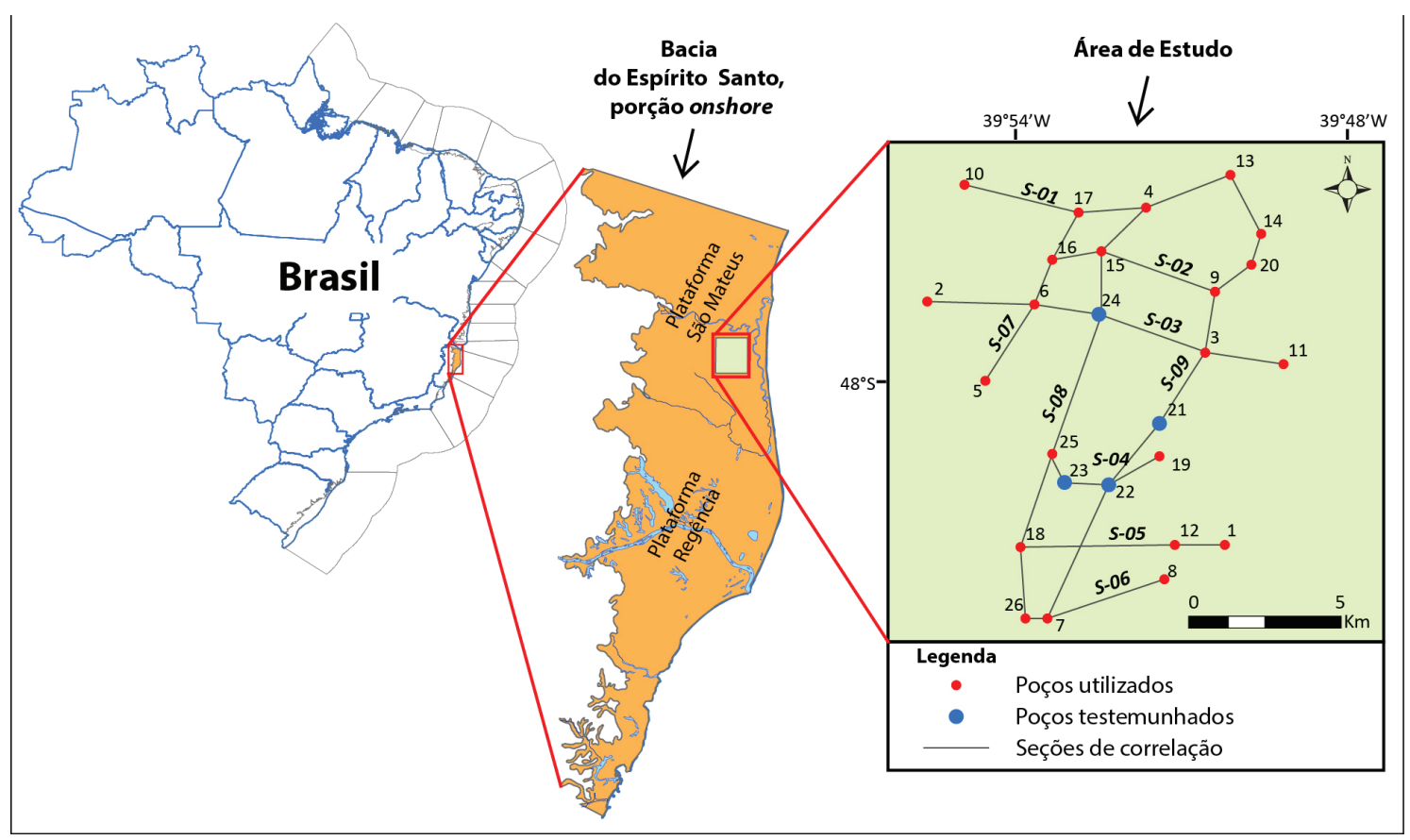

Figura 2. Localização da Bacia do Espírito Santo e da área de estudo com poços e seções de correlação. Figure 2. Location of the Espírito Santo Basin and the study area with wells and correlation sections.

básicos utilizados neste trabalho totalizou 25 poços com uma suíte de perfis elétricos, 4 deles com testemunhagem.

\subsubsection{Descrição de testemunhos}

Utilizando-se de uma planilha descritiva para testemunho, os poços foram descritos observando as características como: textura, espessura, estruturas primárias e secundárias, cor, bioturbação e processos diagenéticos. Ao todo foram levantado $160 \mathrm{~m}$ de testemunho na escala 1:50. Nesta etapa os testemunhos foram calibrados com os perfis de raio gama.

\subsubsection{Análise faciológica}

Os atributos que definem a fácies são: cor, geometria, composição, textura, estruturas sedimentares e conteúdo fossilífero (Walker, 1992). Neste trabalho as fácies foram agrupadas segundo o código proposto por Miall (1996) em sistemas fluviais, usando duas letras como código. A primeira letra é maiúscula e indica o tamanho de grão dominante, onde $G=$ gravel (cascalho), $S=$ sand (areia) e $F=$ fine-grained (areia muito fina, silte e argila) e a segunda letra é minúscula e indica textura ou estrutura, como exemplo, $p$ = estratificação cruzada planar (planar cross-bedding). As características sedimentares secundárias como bioturbação, fósseis e processos diagenéticos não foram utilizados na nomenclatura das fácies, visto que estes atributos não são influenciados pelos processos sedimentares primários, vinculados à deposição dos sedimentos.

\section{Resultados e discussões}

\subsection{Sedimentologia: fácies, associação de fá- cies}

A análise das fácies compreendeu 0 reconhecimento de 12 litofácies (Figura 3 e Quadro 1), que foram agrupadas em quatro associações de fácies distintas: (1) sabkha costeiro, (2) lago alcalino, (3) canais fluviais e (4) depósitos externos aos canais fluviais (overbank). A descrição das litofácies é mostrada na tabela 1 e é baseada na tabela original de Miall (1996) e o sumário das associações de fácies é apresentado no Quadro 2. 


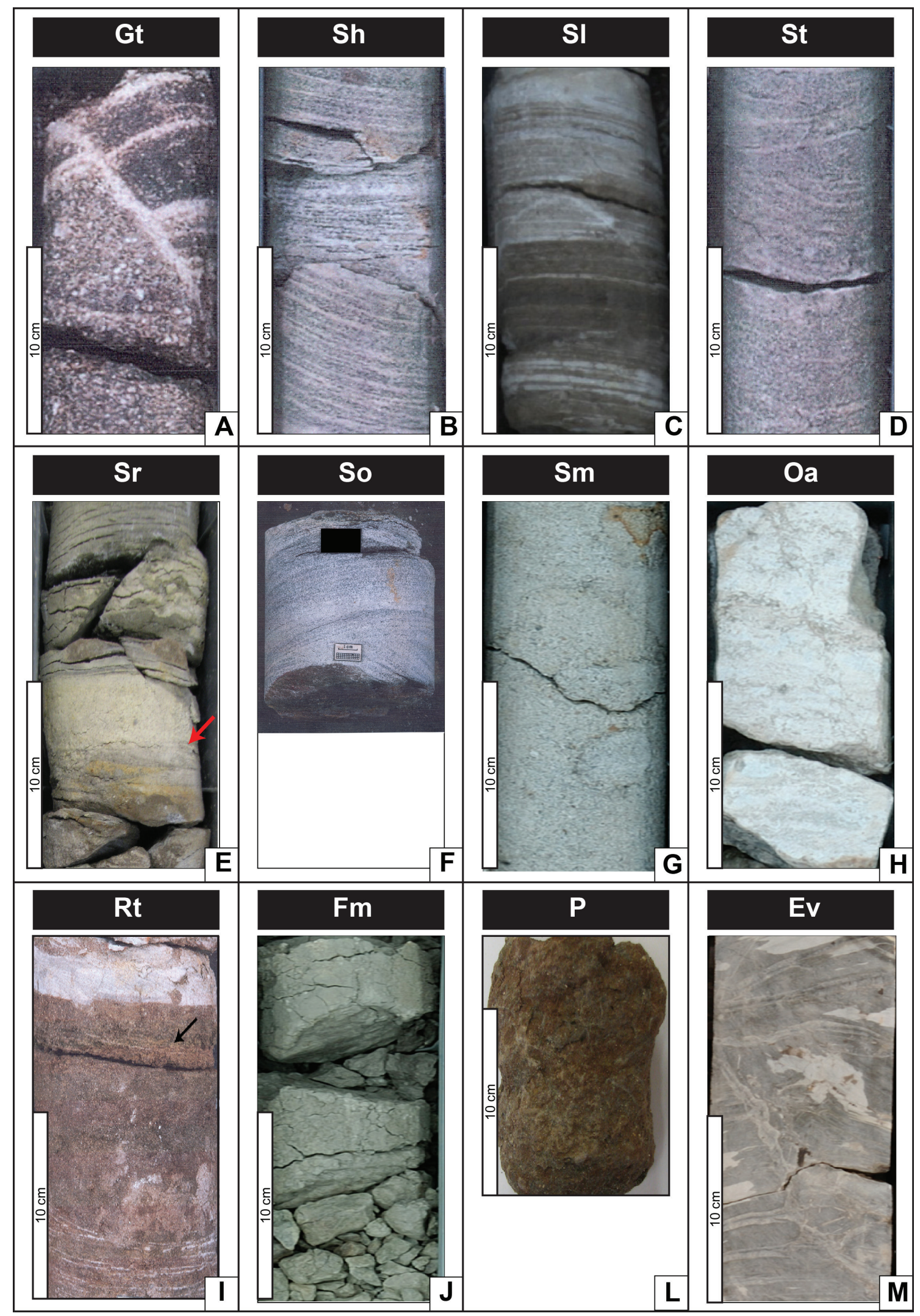

Figura 3. Litofácies descritas. A) Gt: conglomerado clasto suportado com estratificação cruzada; B) Sh: Arenito com laminação plano-paralela; C) Sl: arenito com estratificação cruzada de baixo ângulo; D) St: arenito com estratificação cruzada acanalada; E) Sr; arenito com ripples; F) So: arenito com laminação ondulada truncada; G) Sm: arenito maciço; H) Oa: arenito ooidal intraclástico maciço; I) Rt: Ritmito; J) Fm: Pelito maciço; L) P. Paleosolo de pelitos avermelhados. M) Ev: Anidrita

Figure 3. Lithofacies described. A) Gt: clasto conglomerate supported with cross stratification; B) Sh: Sandstone with plane-parallel lamination; C) Sl: low-angle cross-stratification sandstone; D) St: sandstone with cross stratification; E) Sr; sandstone with ripples; F) So: sandstone with truncated lamination; G) Sm: massive sandstone; H) Oa: massive ooidal sandstone intraclastic; I) Rt: Rhythmic; J) Fm: Massive pelite; L) P. Paleosol. M) Ev: anhydrite. 
Quadro 1. Descrição e interpretação das fácies sedimentares com seus respectivos códigos e interpretação sobre os processos geradores.

Chart 1. Sedimentary facies with respective codes and interpretation of the formative processes.

\begin{tabular}{|c|c|}
\hline DESCRIÇÃO & INTERPRETAÇÃO \\
\hline \multicolumn{2}{|l|}{ Conglomerado } \\
\hline $\begin{array}{l}\text { Gt: Conglomerado clasto-suportado. Grãos sub-anguloso e sub-arredondado } \\
\text { de quartzo }(1-3 \mathrm{~cm}) \text {, Com estratificação cruzada acanalada. }\end{array}$ & $\begin{array}{l}\text { Preenchimento de pequenos } \\
\text { canais ou migração de barras } \\
\text { transversais. }\end{array}$ \\
\hline \multicolumn{2}{|l|}{ Arenito } \\
\hline $\begin{array}{l}\text { Sh: Arenito muito fino a fino bem selecionado com laminação plano- } \\
\text { paralela. Por vezes piritoso. }\end{array}$ & $\begin{array}{l}\text { Fluxo em leito plano, regime de } \\
\text { fluxo superior. }\end{array}$ \\
\hline $\begin{array}{l}\text { Sl: Arenito fino a conglomerático, mal selecionado, por vezes com } \\
\text { fragmentos carbonosos (até } 5 \mathrm{~cm}) \text {. e nódulos de concreções carbonáticas, } \\
\text { piritoso. Clastos a seixos }(0,5-5 \mathrm{~cm}) \text { de feldspatos e quartzo sub-anguloso e } \\
\text { sub-arredondado, dispersos ou, por vezes, acompanhando a estratificação de } \\
\text { baixo ângulo. }\end{array}$ & $\begin{array}{l}\text { Formas de leito atenuadas } \\
\text { (humpback dunes), transição do } \\
\text { regime de fluxo inferior e } \\
\text { superior. }\end{array}$ \\
\hline $\begin{array}{l}\text { St: Arenito fino a conglomerático, mal selecionado. Por vezes com } \\
\text { fragmentos carbonosos. Clastos a seixos }(0,5-5 \mathrm{~cm}) \text { de Feldspato e Quartzo } \\
\text { sub-angulosos e sub-arredondado, dispersos e por vezes acompanhando a } \\
\text { estratificação cruzada acanalada. (Sets variando de } 5-30 \mathrm{~cm}) \text {. }\end{array}$ & $\begin{array}{l}\text { Migração de dunas 3D, regime } \\
\text { de fluxo inferior. }\end{array}$ \\
\hline $\begin{array}{l}\text { Sr: Arenito muito fino a fino, bem selecionado. Por vezes apresenta níveis } \\
\text { de minerais pesados marcando a laminação cruzadas de marcas onduladas } \\
\text { (sets variando de } 5-10 \mathrm{~cm} \text { ) com ângulo de cavalgamento subcrítico a } \\
\text { supercrítico. }\end{array}$ & $\begin{array}{l}\text { Migração e cavalgamento de } \\
\text { marcas onduladas com ângulo } \\
\text { de cavalgamento variado. } \\
\text { Regime de fluxo inferior. }\end{array}$ \\
\hline $\begin{array}{l}\text { So: Arenito muito fino a fino, bem selecionado. Por vezes piritoso, micáceo, } \\
\text { sulfetado. Amarelo-esverdeado, cinza-esverdeado. Laminação ondulada } \\
\text { truncada. }\end{array}$ & $\begin{array}{l}\text { Fluxo oscilatório. Ação de } \\
\text { ondas normais e tempestade. }\end{array}$ \\
\hline $\begin{array}{l}\text { Sm: Arenito Fino a Grosso. Por vezes com fragmentos carbonosos, piritoso, } \\
\text { cimentado (argila e/ou carbonato), marcas de raízes, intraclasto de } \\
\text { carbonato }(2 \mathrm{~cm}) \text {. Maciço ou laminação indistinta. Por vezes bioturbação, } \\
\text { estruturas deformacionais (fluidização). }\end{array}$ & $\begin{array}{l}\text { Depósitos de fluxos } \\
\text { hiperconcentrados, fluidização } \\
\text { ou intensa bioturbação. }\end{array}$ \\
\hline \multicolumn{2}{|l|}{ Arenito Ooidal-Intraclástico } \\
\hline $\begin{array}{l}\text { Ao: Arenito ooidal intraclástico provavelmente de argila magnesiana (talco- } \\
\text { estevensita ou similar), extensamente substituídos por calcita (Grainstone } \\
\text { Oolitíco (Calcarenito espatíco oolitíco)) oóides substituído por calcita em } \\
\text { mosaico grosso e cimentado por franjas prismáticas de calcita. Estes ooídes } \\
\text { originalmente eram de composição argilosa. Maciço. }\end{array}$ & Lago alcalino. \\
\hline \multicolumn{2}{|l|}{ Pelito } \\
\hline $\begin{array}{l}\text { Rt: Ritmitos formado pela intercalação centimétrica }(<10 \mathrm{~cm}) \text { de arenitos } \\
\text { muito finos e pelitos. Acamadamento ondulado ou lenticular. Laminações } \\
\text { cruzadas de marcas onduladas nos arenitos e laminação plano-paralela nos } \\
\text { pelitos. }\end{array}$ & $\begin{array}{l}\text { Rápida desaceleração de fluxos } \\
\text { turbulentos. }\end{array}$ \\
\hline Fm: Pelito avermelhado maciço. & $\begin{array}{l}\text { Assentamento gravitacional de } \\
\text { partículas em suspensão. }\end{array}$ \\
\hline $\begin{array}{l}\text { P: Paleossolo de pelitos avermelhados com grãos de areia dispersos. } \\
\text { Maciço. Presença de marcas de raízes e planos de deformação e feições } \\
\text { pedogênicas, como nódulos de siltito. }\end{array}$ & $\begin{array}{l}\text { Resultado de oxidações, } \\
\text { lixiviação e outros processos } \\
\text { superficiais geradores de } \\
\text { horizontes de solo. }\end{array}$ \\
\hline \multicolumn{2}{|l|}{ Evaporito } \\
\hline $\begin{array}{l}\text { Ev: Anidrita, branca a cinza-escuro. Presença de fraturas com precipitação } \\
\text { de sal. Maciço. }\end{array}$ & 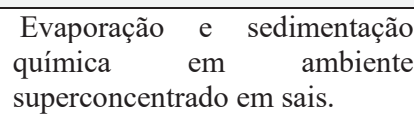 \\
\hline
\end{tabular}


Quadro 2. Sumário das associações de fácies e litofácies constituintes.

Chart 2. Summary of facies association and lithofacies.

\begin{tabular}{|l|l|}
\hline ASSOCIAÇÕES DE FÁCIES & $\begin{array}{l}\text { LITOFÁCIES } \\
\text { CONSTUINTES }\end{array}$ \\
\hline Sabkha costeiro & $\mathrm{Ev}, \mathrm{Fm}$ \\
\hline Lago alcalino & $\mathrm{So}, \mathrm{Sm}, \mathrm{Oa}$ \\
\hline Canais fluviais & $\mathrm{Gt}, \mathrm{Sh}, \mathrm{Sl}, \mathrm{St}, \mathrm{Sr}$ \\
\hline $\begin{array}{l}\text { Depósitos externos aos canais } \\
\text { fluviais (Overbank) }\end{array}$ & $\mathrm{Sr}, \mathrm{Rt}, \mathrm{Fm}, \mathrm{P}$ \\
\hline
\end{tabular}

\subsubsection{Associação de fácies de Sabkha costeiro}

Esta associação de fácies é caracterizada pela intercalação de pacotes tabulares de evaporitos (Ev) com finas camadas de pelitos maciços (Fm) com espessuras variando de 0,3 a $10 \mathrm{~m}$. Os pacotes de evaporitos apresentam espessuras de $10 \mathrm{~m}$ até $60 \mathrm{~m}$ de espessura. Esta associação ocorre na base da seção em toda área estuda.

Os evaporitos são precipitados como nódulos de anidrita que coalesceram de forma maciça em diversos intervalos. Isso ocorreu em sedimentos dominantemente lamosos (fácies Fm). Esses depósitos lamosos foram sedimentados provavelmente em corpos lacustres efêmeros de pequena profundidade.

\subsubsection{Associação de fácies de lago alcalino}

Essa associação de fácies é composta por arenitos muito finos a finos com laminação ondulada truncada (So) e arenitos finos maciços (Sm). Essaslitofácies sesobrepõem verticalmente formando sucessões com até $2 \mathrm{~m}$ de espessura. Em um intervalo específico (poço 22, a 690 m), ocorre uma camada, de $1 \mathrm{~m}$ de espessura, de arenito fino, com ooides argilosos, maciço e com uma intensa cimentação de calcita (litofácies Oa). Em perfil este depósitos são caracterizados por um pico de baixos valores de raio-gama, que pode ser identificado em poços adjacentes.

A ocorrência de arenito fino com oóides de composição original argilosa com estrutura maciça denota ambiente com baixa energia. A presença exclusiva de oóides argilosos esmectíticos indica um contexto lacustre alcalino de baixa salinidade (Tettenhorst \& Moore Jr., 1978; Pozo \& Casas, 1999). A inexistência de fósseis indicativos de ambiente marinho favorece a interpretação de um contexto lacustre. Os depósitos siliclásticos maciços e com laminações onduladas truncadas por ondas que ocorrem adjacentes aos arenitos ooidais indicam a ação de ondas normais e/ ou de tempestades nas porções mais rasas dos corpos lacustres. A correlação lateral desta associação de fácies por distâncias significativas (5 km) aponta para existência de corpos lacustre amplos, de grande extensão lateral.

\subsubsection{Associação de fácies de canais fluviais}

Essa associação de fácies é composta por conglomerados com laminação cruzada tangencial(Gt), arenitos finos a muito grossos com estratificações cruzadas tangenciais (litofácies St), arenitos finos a grossos com laminações horizontais (litofácies Sh) e de baixo ângulo (SI) e arenitos muitos finos e siltitos com laminações cruzadas de marcas onduladas (litofácies Sr). As litofácies se sobrepõem verticalmente formando ciclos de granodecrescência ascendente, com espessuras variando de 2 a $5 \mathrm{~m}$, caracterizados normalmente por Gt na base, sobreposto pelas litofácies St, SI e Sh, podendo ocorrer, a litofácies Sr no topo. Entretanto, alguns ciclos não apresentam a litofácies Gt na base, sendo constituídos somente pelas litofácies arenosas.

A presença de sucessões de fácies com granodecrescência ascendente com base erosiva, composta internamente por arenitos mal selecionados, com estratificações cruzadas acanaladas e de baixo-ângulo, estratos horizontais e laminações cruzadas de marcas onduladas permitem interpretar esta associação de fácies como depósitos de canais fluviais. A presença de formas de leito no fundo do canal formadas em diferentes regimes de fluxo indica flutuações na velocidade da corrente, associadas a variações na descarga ou na profundidade do canal. Os ciclos de granodescrescência ascendente que caracteriza os depósitos de canais descritos podem representar: (a) migração lateral de barras em pontal ou (b) progressiva diminuição da velocidade do fluxo associado 
durante o preenchimento vertical do canal fluvial. A granulometria grossa e o domínio de estruturas trativas indicam que os sedimentos foram transportados no canal dominantemente como carga de fundo, o que permite classificar estes depósitos como sistemas fluviais de carga de fundo (bed-load fluvial systems) segundo a classificação de Schumm (1968). A reconstrução da morfologia dos canais com base em dados de supersuperfície 1D é complexa, segundo Bridge (2006), visto que tanto os depósitos de canais meandrantes quanto os de canais entrelaçados podem gerar sucessões granodecrescentes.

\subsubsection{Associação de fácies de Depósitos exter- nos aos canais fluviais (Overbank)}

Esta associação de fácies é composta por arenitos muito finos a finos com ripples com ângulo de cavalgamento subcrítico a supercrítico (Sr), Ritmitos composto por camadas milimétricas a centimétrica de arenito muito fino com laminação cruzada de marcas onduladas intercalado com pelitos com laminação planoparalela (Rt), Pelito maciço (Fm) e paleossolos pelítico ou síltico $(P)$. As litofácies se sobrepõem verticalmente formando sucessões com até $2 \mathrm{~m}$, caracterizados normalmente por $\mathrm{Sr}$ na base, sobreposto pelas litofácies Rt e Fm, mais raramente pode ocorrer a litofácies $\mathrm{P}$ no topo.

A presença de sucessões de fácies, composta internamente por arenitos muito finos a finos bem selecionados, com marcas onduladas assimétricas, intercalados com pelitos maciços e paleossolos, permite interpretar esta associação como depósitos de áreas externas aos canais (overbank areas). Segundo Collison (1996), os depósitos externos aos canais podem ser separados em depósitos de áreas próximas de canais ativos (que incluem os diques marginais e os depósitos de crevasse) ou as áreas distantes de canais ativos, a planície de inundação. A dominância de ritmitos areno-pelíticos sugere que esta associação representa depósitos de extravasamento de crevasses (Miall, 1996).

\subsection{Correlação estratigráfica}

O estabelecimento de um arcabouço estratigráfico de alta resolução no intervalo analisado é extremamente difícil diante de uma série de limitações quando se trabalha exclusivamente com dados de poços. Diferentes trabalhos têm demonstrado a aplicabilidade dos conceitos da estratigrafia de sequências em sucessões aluviais, tendo como base 0 reconhecimento de discordâncias que separam diferentes sequências deposicionais (e.g. Shanley \& McCabe, 1993, 1994; Miall, 1996; Plint et al., 2001). A identificação de discordâncias em sucessões fluviais leva em conta uma série de critérios, entre os quais se pode destacar: mudança abrupta de fácies, relevo e extensão lateral da superfície erosiva; alterações nos padrões de paleocorrentes e mudanças na proveniência (Wright \& Marriot, 1993; McCarthy \& Plint, 1998; McCarthy et al., 1999). Entretanto, os dados listados acima são possíveis de serem extraídos de seções aflorantes ou a partir de uma malha de poços pouco espaçada e com testemunhagem contínua, o que não reflete a situação da área de estudo. Como, na área em estudo, o espaçamento entre os poços é grande (média de $3 \mathrm{~km}$ ) e a testemunhagem é descontínua e com pouca continuidade vertical, a identificação e correlação de discordância tornase inviável, carregando um grau de imprecisão muito grande. Em decorrência disso, o método mais adequado para o fatiamento estratigráfico dos depósitos fluviais da Formação São Mateus, consiste na identificação e correlação com base em perfis e testemunhos de tendências de aumento e diminuição no grau de amalgamação dos depósitos de canais fluviais, que por sua vez, refletem um aumento e diminuição na razão entre a taxa de acomodação (A) e a taxa de influxo sedimentar (S), respectivamente. Este padrão pode ser definido nos perfis de raios gama (RG) com certa facilidade, onde os corpos arenosos de canais fluviais apresentam menores valores de $R G$, definindo um padrão em caixote ou sino invertido. Os depósitos externos aos canais, por sua vez, apresentam valores mais altos de RG, definindo um padrão serrilhado no perfil.

O fatiamento estratigráfico apresenta diferentes intervalos de aumento e diminuição no grau de amalgamação dos corpos arenosos de canais fluviais. Desta forma, mantém no seu 
embrião a premissa fundamental da estratigrafia de sequências de que as variações na razão A/S controlam o empilhamento estratigráfico de sucessões aluviais. A limitação desta técnica de correlação consiste no fato dos limites dos intervalos não materializarem necessariamente superfícies estratigráficas chave. Estes horizontes de correlação representam tão somente mudanças nos padrões de empilhamento, sendo marcados no meio do pacote de máxima amalgamação dos corpos arenosos, não correspondendo, na maioria das vezes, a superfícies físicas existentes na sucessão de rocha. Ou seja, os horizontes de correlação não têm um significado cronoestratigráfico, podendo inclusive cortar superfícies discordantes que marcam limites de sequências (Fig. 4). Apesar desta limitação, pode-se considerar esta técnica de correlação mais parcimoniosa, fundamentada nos conjuntos de dados existentes. A identificação e correlação forçosa de superfícies de discordância podem gerar a falsa impressão de um arcabouço estratigráfico mais sólido, escondendo uma imprecisão muitas vezes não esclarecida devidamente nos trabalhos que aplicam a estratigrafia de sequências em sucessões aluviais. Embora os limites dos intervalos de aumento e diminuição na razão A/S não sejam precisos, a delimitação desses intervalos e o agrupamento em ciclos, permitem o entendimento da dinâmica de acumulação de sedimentos, além de estabelecer modelos preditivos do grau de conectividade lateral e vertical dos corpos arenosos de canais fluviais ao longo de cada intervalo analisado.

A Formação São Mateus apresenta um contato discordante com a Formação Itaúnas. A Formação Itaúnas é caracterizada por evaporitos e folhelhos, associados a um ambiente marinho restrito e de sabkas marginais, enquanto a Formação São Mateus é composta essencialmente por estratos aluviais (associações de fácies de canais e de depósitos externos aos canais) e, localizadamente, por depósitos lacustres (associação de fácies de lago alcalino). O contato entre estas unidades é marcado por uma superfície erosiva, de extensão regional, identificado em todos os poços descritos (Fig. 5).
A sucessão aluvial da Formação São Mateus é caracterizada pela alternância de intervalos de aumento ou diminuição da razão entre os depósitos da associação de fácies de canais fluviais e os depósitos das associações de fácies externas aos canais, de forma similar ao que foi observado em diferentes exemplos descritos na bibliografia (e.g. Martinsen et al., 1999; Ramón \& Cross, 1997) (Fig. 6) Com base nisto foram individualizados seis ciclos da base da Formação São Mateus até a base do Grupo Rio Doce, sendo que os dois primeiros foram observados em testemunho (poço 22). Cada ciclo é composto internamente por um intervalo de diminuição (base) seguindo por aumento (topo) no grau de amalgamação e na granulometria dos

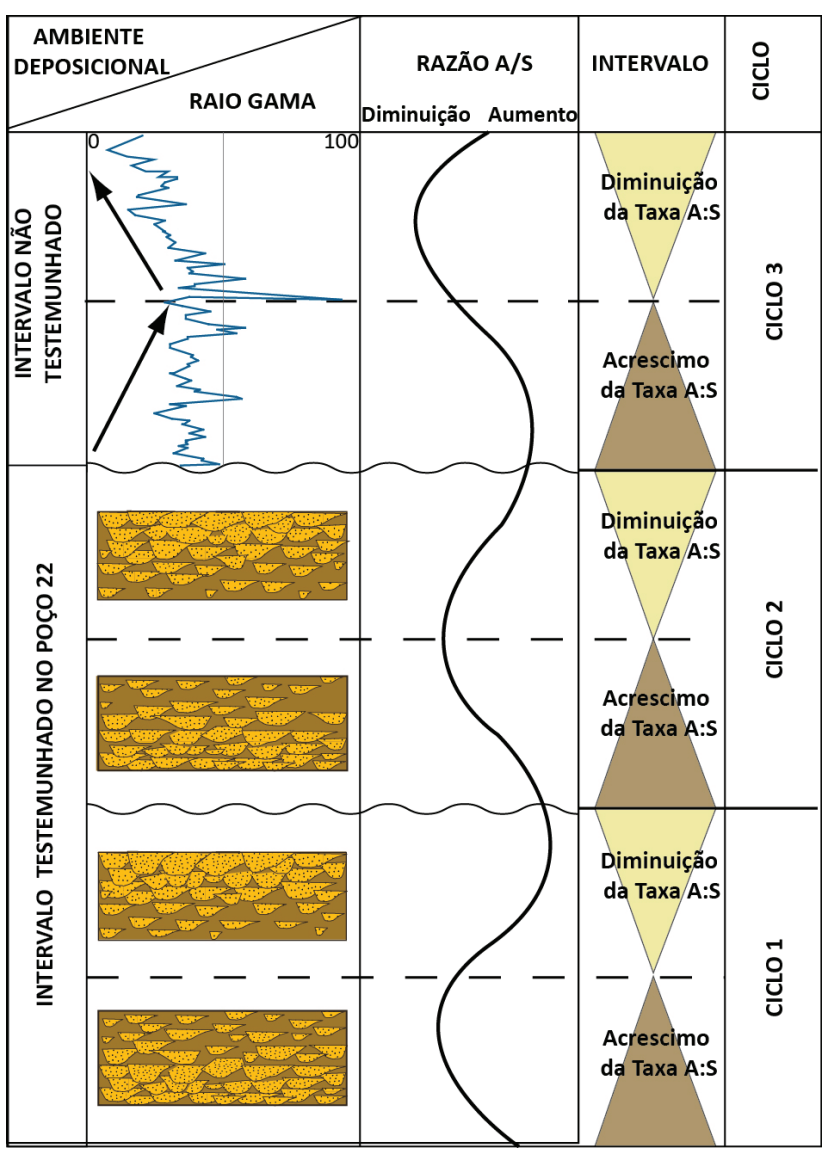

Figura 4. Modelo conceitual da relação entre o limite de sequências (sem expressão correlacionável em poços) e o limite de ciclos A/S (não possui resolução cronoestratigráfica, porém representa tendências correlacionáveis nos poços).

Figure 4. Conceptual model of the relationship between the sequence limit (no correlated expression in wells) and the A / S cycle limit (it does not have chronostratigraphic resolution, but represents correlations trends in the wells). 

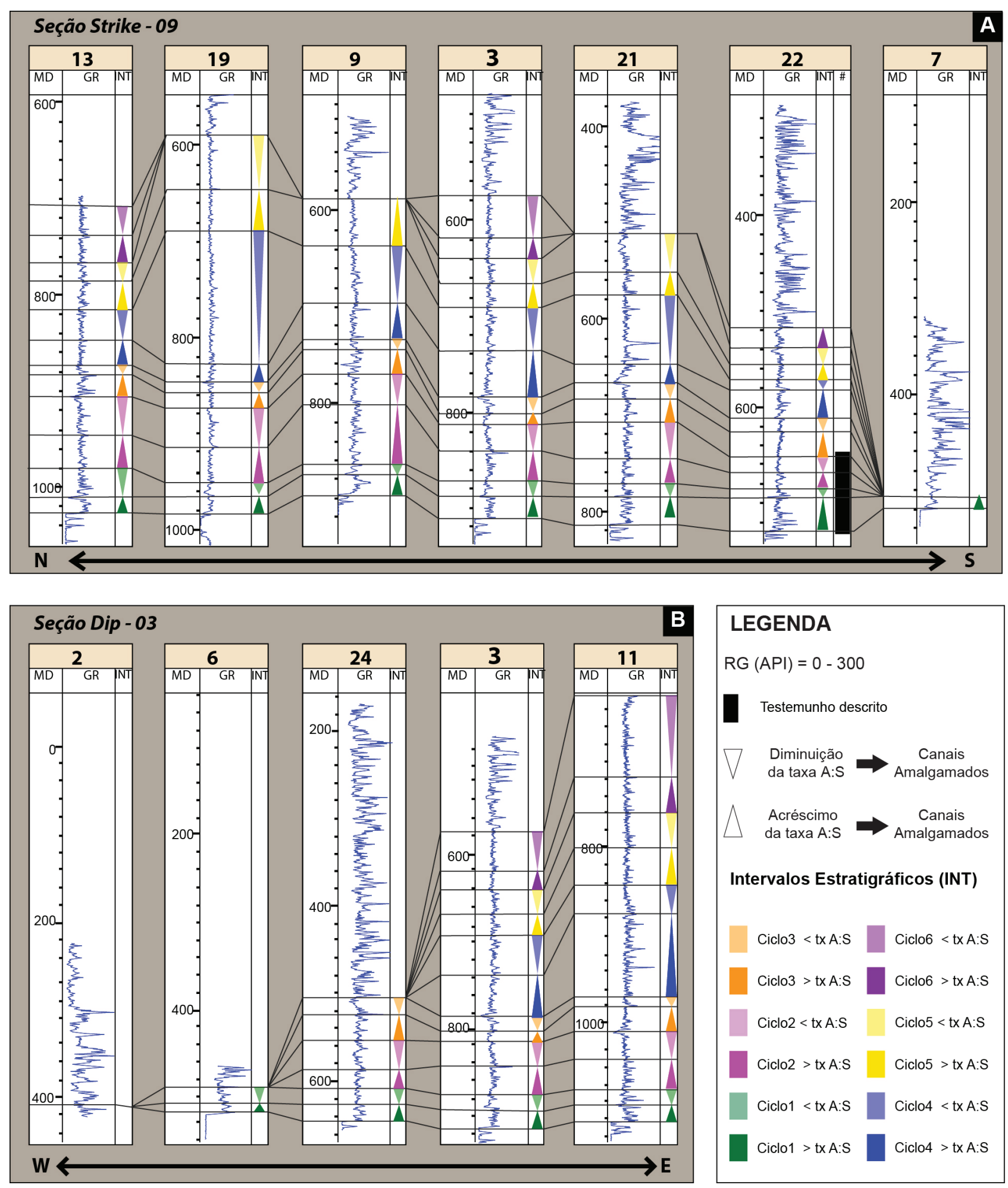

\section{Intervalos Estratigráficos (INT)}

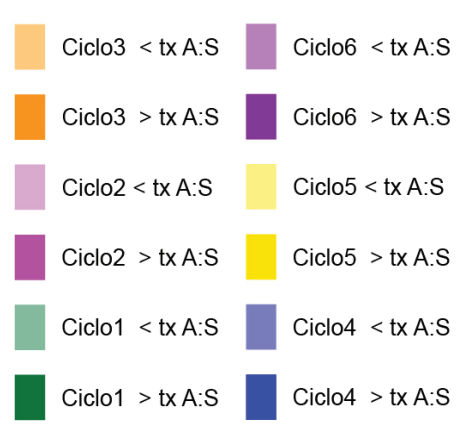

Figura 5. Arcabouço Estratigráfico no intervalo da Formação São Mateus, Grupo Barra Nova - Bacia do Espírito Santo. A) Seção Strike 09; B) Seção Dip 03.

Figure 5. Stratigraphic framework in the interval of the São Mateus Formation, Barra Nova Group - Espírito Santo Basin. A) Strike section 09; B) Dip section03. 


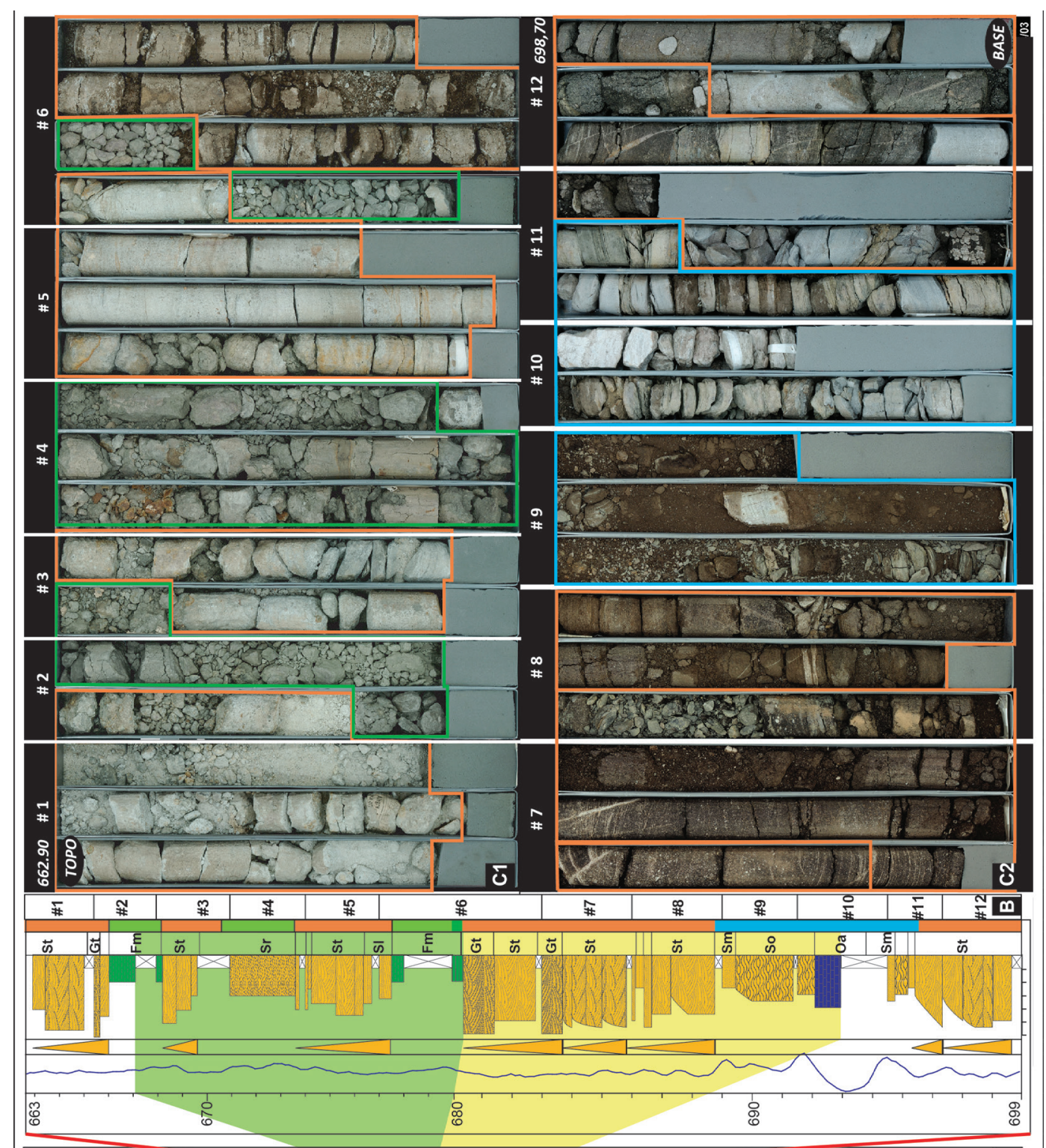

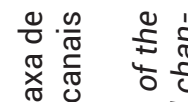

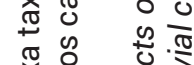

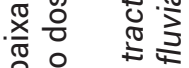

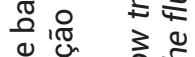

ฮี

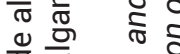

पू है

$\frac{\pi}{\pi} \frac{\pi}{0}$

쥰 $\frac{\pi}{0} \stackrel{0}{5}$

\% 유 율

(ब) is

$\frac{1}{\pi}$ 응

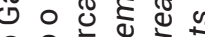

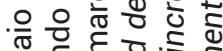

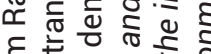

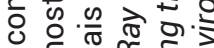
ฟ

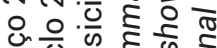
․ㅡㅇ 응 응 훙 눈 สั

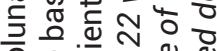

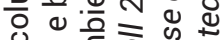

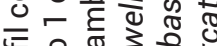

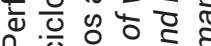
₹

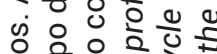

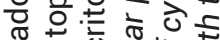

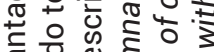
원응 응 ल워웡 亭岂志志 중 की Q क ष

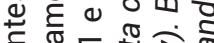

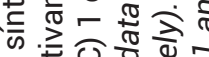
बृ

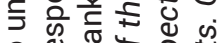
은 은

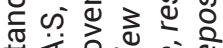

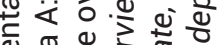
ब d

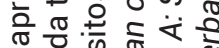
ㄴ.

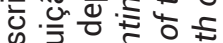

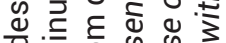

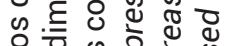

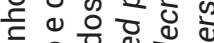

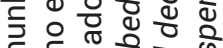

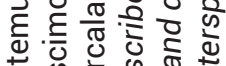
की क ๘

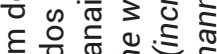

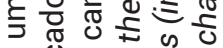
ข 을 है ब

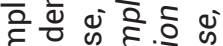

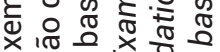

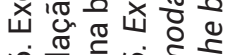

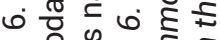
๘

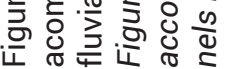

\begin{tabular}{|c|c|c|c|c|c|c|c|c|c|c|c|c|c|c|}
\hline 芩 & 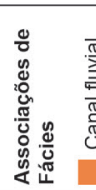 & 迹 & 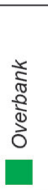 & 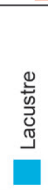 & 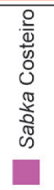 & 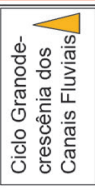 & 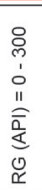 & 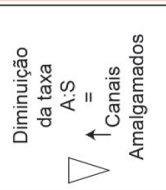 & 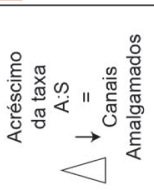 & 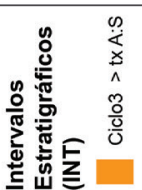 & 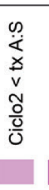 & 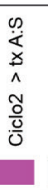 & 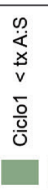 & 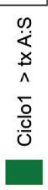 \\
\hline
\end{tabular}




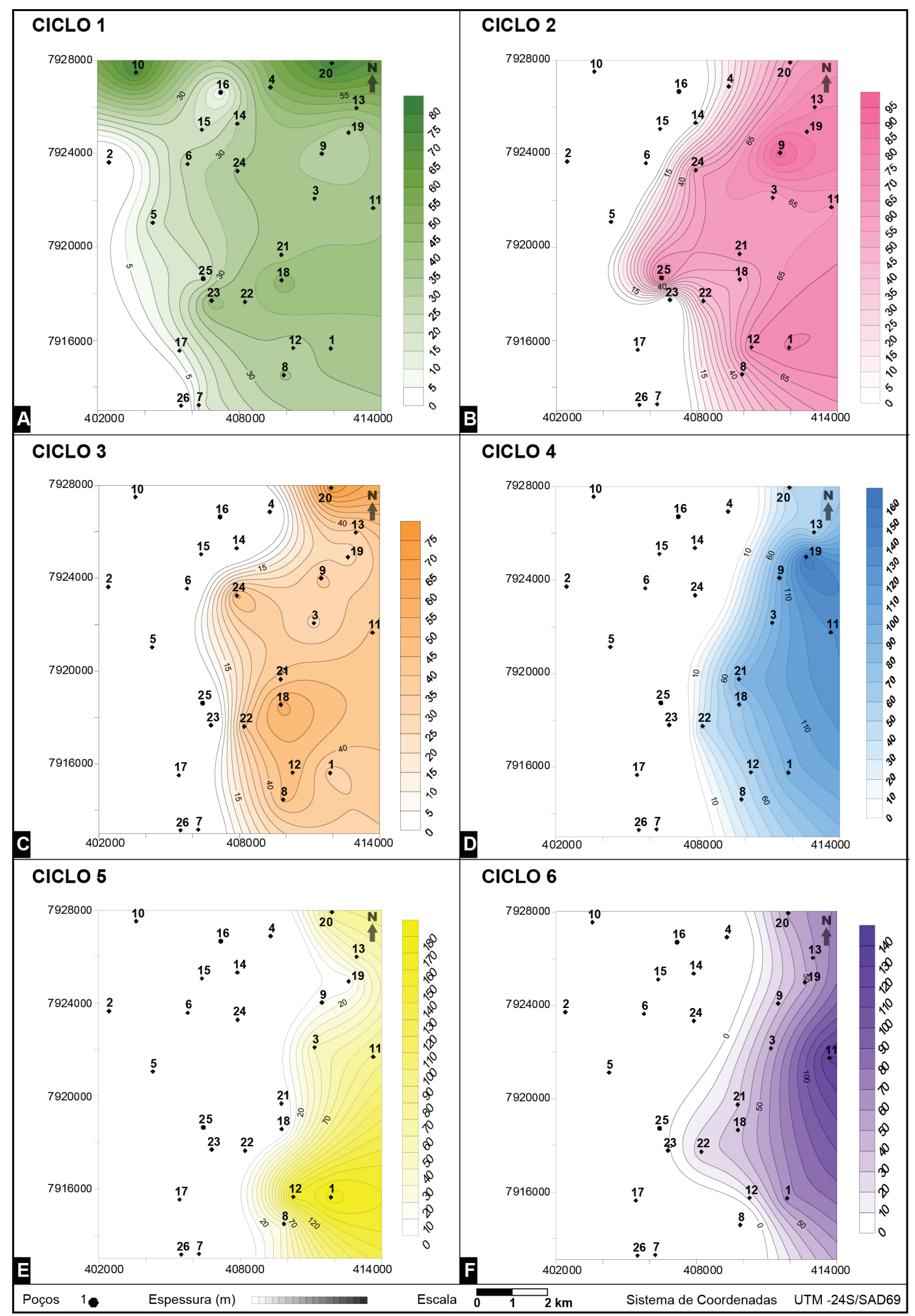

Figura 7. Mapas de Isópacas construída a partir da soma das espessuras dos depósitos de canais fluviais e overbank. A) e B) Ciclos 1 e 2 construídos com base nas interpretações de testemunhos e perfis RG. Observe a área de erosão, borda oeste da área; C), D) e E) Ciclos 3, 4, 5 e 6 construídos com base nas interpretações de perfis RG.

Figure 7. Maps of Isopacs constructed from the sum of the thicknesses of deposits of fluvial channels and overbank. A) and B) Cycle 1 and 2 based on interpretations of cores and RG curve. Note the erosion area, west boundary of the area.C), D) and E) Cycles 3, 4, 5 and 6 constructed based on the interpretations of RG curves. 
corpos arenosos de canais fluviais, podendo ser definidos tanto em testemunho, quanto nos perfis de raio gama (Figs. 5 e 6). Estas variações no grau de amalgamação e granulometria dos corpos arenosos de canais fluviais refletem mudanças na razão acomodação/suprimento sedimentar (A:S) (Ramón \& Cross, 1997). O intervalo inferior representa um progressivo acréscimo na taxa $A: S$, enquanto o intervalo superior reflete uma tendência de diminuição na taxa A:S, permitindo o fatiamento estratigráfico do intervalo de interesse tendo como base os conceitos fundamentais da estratigrafia de sequências (Catuneanu, 2006).

O contato superior da Formação São Mateus com a Formação Rio Doce (na Bacia do Espírito Santo) é marcado por uma desconformidade, fortemente erosiva, passível de correlação regional. A erosão se torna mais pronunciada em direção a oeste (Fig. 7), podendo acarretar na total ausência da Formação Mateus (Fig. 5 A e B) (erosão total da Formação São Mateus), diminuindo progressivamente em direção a leste, sendo que nos poços 11 e 13 (Fig. 5) podem-se observar os seis ciclos fluviais preservados.

\section{Discussão dos resultados e conclusões}

O modelo evolutivo estratigráfico na área de estudo, porção norte terrestre da Bacia do Espírito Santo foi baseado na distribuição espacial dos canais fluviais. A estruturação do arranjo da amalgamação dos canais fluviais com os depósitos externos aos canais (overbank) reflete a razão entre a taxa de acomodação (A) e a taxa de influxo sedimentar (S) formando ciclos (Fig. 8). Esta taxa está associada às variações do perfil de equilíbrio, no caso de sedimentos aluviais próximo à costa (Shanley \& McCabe, 1993; Catuneanu, 2006). Diversos estudos (Shanley \& McCabe, 1993, 1994; Wright \& Marriot, 1993) demonstraram que em sistemas fluviais acumulados próximo à costa, o nível relativo do mar controla o comportamento do perfil de equilíbrio, determinando o padrão de empilhamento dos depósitos fluviais. As variações na razão entre as taxas de criação de acomodação/suprimento sedimentar (A:S) controlou o grau de amalgamação dos corpos arenosos dos canais fluviais. Intervalos caracterizados por corpos arenosos de canais fluviais, lateral e verticalmente amalgamados, com ausência ou raras ocorrências de depósitos externos aos canais, indicam um contexto de baixa razão A:S. Por outro lado, sucessões aluviais com corpos arenosos isolados e/ou intercalados com abundantes depósitos externos aos canais fluviais indicam que a acumulação fluvial ocorreu em um contexto de alta razão A:S.

Com base neste controle de taxa A:S, nos poços testemunhados e nos perfis de raios gama a sucessão aluvial mostra ciclos de variações no grau de amalgamação dos canais. Cada ciclo é composto internamente por um intervalo de aumento (base) seguindo por um intervalo de diminuição (topo) no grau de amalgamação dos canais fluviais, refletindo variações na taxa A:S. O intervalo inferior representa um progressivo acréscimo na taxa A:S, enquanto o intervalo superior reflete uma tendência de diminuição na taxa A:S, trato de alta taxa de acomodação e trato de baixa taxa de acomodação, respectivamente. Estes ciclos podem ser considerados intervalos estratigráficos, pois apresentam um vínculo

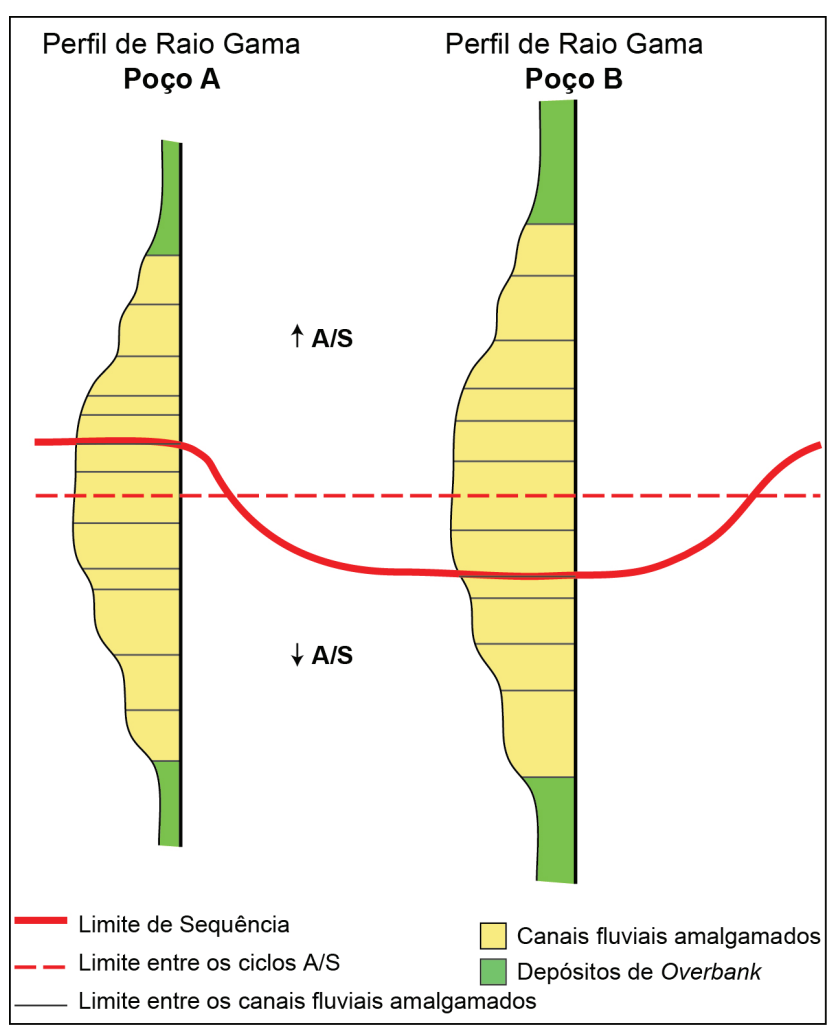

Figura 8. Modelo esquemático da evolução estratigráfica dos depósitos fluviais no intervalo de estudo.

Figure 8. Schematic model of the stratigraphic evolution of the fluvial deposits in the study interval. 
genético com as variações do nível de base na bacia, sendo passíveis de correlação lateral. Isso forma a base de uma técnica de correlação genética alternativa à litoestratigrafia, sustentada nas premissas fundamentais da oscilação do nível de base, e da criação e destruição do espaço de acomodação ao longo do tempo.

Foram individualizados seis ciclos que são compostos internamente por intervalos de aumento (base) e diminuição (topo) no grau de amalgamação dos canais fluviais. Os dois primeiros ciclos foram observados nos poços descritos, enquanto os demais foram definidos somente com base em perfis. Estes ciclos superiores foram fortemente erodidos pelos arenitos fluviais da Formação Rio Doce, principalmente na porção oeste da subárea sul.

Adicionalmente, na porção terrestre da Bacia do Espírito Santo mais à sul da área de estudo (região da Plataforma de Regência), ocorrem uma complexa intercalação em alta frequência entre sedimentos carbonáticos e siliciclásticos estruturados em ciclos (Tagliari, 1993). A deposição desses sedimentos costeiros, segundo Tagliari (1993), é controlada pelo nível de base e a mistura dos sedimentos carbonáticos e siliciclásticos por variações eustáticas orbitalmente induzidas a nível de $4^{\circ}$ e $5^{\circ}$ ordem (Ciclos de Milankovitch). Estes ciclos carbonáticos e siliciclásticos apresentam uma correlacionabilidade direta com os ciclos A:S mapeados em testemunhos do sistema exclusivamente fluvial. Desta maneira, o nível de base está diretamente associado na deposição dos sedimentos costeiros na Plataforma de Regência, enquanto na área de estudo (porção terrestre norte), o perfil de equilíbrio controla a deposição dos depósitos fluviais, indicando uma relação direta entre os depósitos continentais e costeiros e o nível relativo do mar, com seu reflexo na variação direta do nível do mar nos depósitos costeiros carbonáticos, e no perfil de equilíbrio dos depósitos fluviais.

É comum a elaboração de arcabouços estratigráficos em ambientes costeiros, com diversos trabalhos publicados. Atualmente, a caracterização de arcabouços, com definição de variáveis controladoras, para sistemas continentais, principalmente fluviais, também já é bem usual. Entretanto, a caracterização de sistemas fluviais com controle direto do nível do mar é ainda algo raro, pois usualmente a definição de ciclos A:S apresenta-se definida, porém sem uma clara conexão com depósitos costeiros. Desta forma, comumente apontase o controle da variação do nível relativo do mar, mas sem uma conexão direta do mesmo. Neste trabalho, os ciclos A:S foram definidos com base em testemunhos, e extrapolados em perfis geofísicos de poço, apresentando uma boa confiança na correlação tridimensional. Este modelo proporcionou uma correlação direta com os depósitos carbonáticos distais (que ocorrem ao sul da área), e assim determina uma correlação direta dos ciclos A:S com uma variação do nível relativo do mar. Estes resultados apresentam dois impactos relevantes: (1) A Formação São Mateus é portadora de reservatórios produtores de petróleo em diversos campos terrestres na Bacia do Espírito Santo, ainda que secundários. A definição de ciclos permite um fatiamento estratigráfico destes depósitos que pode auxiliar na compreensão de unidades de fluxo e fornecer um controle de barreiras e conectividades para a engenharia do reservatório, permitindo uma maior optimização da produção dos intervalos, bem como compreender níveis de baixa produtividade. E (2) fornece um modelo análogo para arcabouço estratigráfico de depósitos fluviais baseado em ciclos A:S, mas com um controle claro e determinado de variação do nível relativo do mar, permitindo assim estabelecer uma relação direta das variáveis que impactam na deposição (A:S) e seus mecanismos controladores (neste caso, nível do mar).

Agradecimentos. Este trabalho é parte integrante da dissertação de mestrado desenvolvido pela primeira autora junto ao Programa de Pós-Graduação em Geociências da UFRGS, realizado no âmbito do projeto "Estudo Integrado estratigráfico e petrológico dos depósitos da Formação São Mateus na área do Projeto Enxofre Itaúnas (PEI) na Bacia do espírito Santo". A primeira autora agradece ao CNPq pela concessão de bolsa de mestrado. Os autores agradecem a PETROBRAS - UN-ES, pela liberação dos dados. 


\section{Referências}

Aitken, J.F. \& Flint, S.S. 1995: The application of high-resolution sequence stratigraphy to fluvial systems: a case study from the Upper Carboniferous Breathitt Group, eastern Kentucky, USA. Sedimentology, 42, 3-30

Bridge, J.S. 2006. Fluvial facies models: recent developments. In: Posamentier, H.W. \& Walker, R.G. (Eds.) Facies Models Revisited. SEPM Special Publication, 84: 85-70.

Catuneanu, O. 2006. Principles of Sequence Stratigraphy. Elsevier, Amsterdam 375p.

Catuneanu, O. \& Sweet, A.R. 1999. MaastrichtianPaleocene foreland basin stratigraphies, Western Canada: A reciprocal sequence architecture. Canadian Journal of Earth Sciences, 36: 685-703.

Catuneanu, O. \& Elango, H.N. 2001. Tectonic control on fluvial styles: the Balfour Formation of the Karoo Basin, South Africa. Sedimentary Geology, 140(3-4): 291-313.

Catuneanu, O., Abreu, V., Bhattacharya, J.P., Blum, M.D., Dalrymple, R.W., Eriksson, P.G., Fielding, C.R., Fisher, W.L., Galloway, W.E., Gibling, M.R., Giles, K.A., Holbrook, J.M., Jordan, R., Kendall, C.G.St.C., Macurda, B., Martinsen, O.J., Miall, A.D., Neal, J.E., Nummedal, D., Pomar, L., Posamentier, H.W., Pratt, B.R., Sarg, J.F., Shanley, K.W., Steel, R.J., Strasser, A., Tucker, M.E., Winker, C., 2009. Towards the standardization of sequence stratigraphy. Earth-Science Reviews, 92: 1-33

Chang, H.K., Kowsmann, R.O. \& Figueiredo, A.M. 1988. New concepts of the development of east Brazilian marginal basins. Episodes, 11: 194-202.

Collinson, J.D. 1996. Alluvial sediments. In: Reading, H.G. (Ed.). Sedimentaryenvironments: processes, facies and stratigraphy. 3rd. ed., London: Blackwell Science, p. 37-82.

Costa, L.R.A. 1988. Evolução termomecânica da Bacia do Espírito Santo. Ouro Preto, 142p. Dissertação de Mestrado, DEGEO/Escola de Minas, Universidade Federal de Ouro Preto.

Currie, B.S. 1997. Sequence stratigraphy of nonmarine Jurassic-Cretaceous rocks, central Cordilleran foreland-basin system. Geological Society of America Bulletin, 109: 1206-1222.
Dalrymple, M., Prosser, J. \& Williams, B. 1998. In: Shanley K.W. \& McCabe P.J. (Eds) SEPM - Special Publication, 59 - Relative role of eustasy, climate, and tectonism in continental rocks. Tulsa, Oklahoma, p. 17-29.

França, R.L., Del Rey, A.C., Tagliari, C.V., Brandão, J.R. \& Fontanelli, P.R. 2007. Bacia do Espírito Santo. Boletim de Geociências, 15(2): 501509.

Galloway, W.E. \& Hobday, D.K. 1996. Terrigenous clastic depositional systems. New York, Springer-Verlarg, 489p

Guerra M.C.M. 1989. A estruturação da Bacia do Espirito Santo por halocinese e influência do vulcanismo dos Abrolhos. Ouro Preto, 125p. Dissertação de Mestrado, DEGEO/Escola de Minas, Universidade Federal de Ouro Preto.

Martinsen, O.J., Ryseth, A., Halland, H.W., Fleshe, H., Torkildsen, G. \& Idil, S. 1999. Stratigraphic base level and fluvial architecture: Ericson Sandsote (Campanian), Rock Springs Uplift, SW yoming, USA. Sedimentology, 46 (2): 235259

McCarthy, P.J. \& Plint A.G. 1998. Recognition of interfluve sequence boundaries: integrating paleopedology and sequence stratigraphy. Geology, 26(5): 387-390.

McCarthy P.J., Faccini U.F. \& Plint G. 1999. Evolution of ancient coastal plain: palaeosols, interfluves and alluvial archictecture in a sequence stratigraphic framework, Cenomanian Dunvegan Formation, NE British Columbia, Canada. Sedimentology, 46(5): 861891.

Miall, A.D. 1996. The Geology of Fluvial Deposits: Sedimentary Facies, Basin Analysis and Petroleum Geology. New York, SpringerVerlag, 582p.

Plint, A.G., Mccarthy, P.J. \& Faccini, U.F. 2001. Nonmarine sequence stratigraphy: Updip expression of sequence boundaries and systems tracts in a high-resolution framework, cenomanian Dunvegan Formation, Alberta foreland basin, Canada. AAPG Bulletin, 85: 1967-2001.

Posamentier, H.W., Jervey, M.T. \& Vail, P.R. 1988. Eustatic Controls on Clastic Deposition I - Conceptual Framework. In: Wilgus, C.K., Hastings, B.S., Kendall, C.G.St.C., Posamentier, 
H.W., Ross, C.A. \& Van Waggoner, J.C. (Eds.). SEPM Special Publication, 42 - Sea-level changes: an integrated approach. Tulsa, SEPM Strata Society for Sedimentary Geology, p. 109-124.

Pozo, M. \& Casas, J. 1999. Origin of kerolite and associated $\mathrm{Mg}$ clays in palustrine-lacustrine environments; the Esquivias Deposit (Neogene Madrid Basin, Spain). Clay Minerals. 34:395418.

Ramón, J.C. \& Cross, T. 1997. Characterization and prediction of reservoir architecture and petrophysical properties in fluvial channel sandstones, middle Magdalena Basin, Colombia. Ciencia, Tecnologia y Futuro, 1(3):122.

Schumm, S.A. 1968, River adjustments to altered hydrologic regimen - Murrumbidgee River and paleochannels, Australia: U.S. Geological Survey Professional Paper 598: 65p.

Shanley, K.W. \& McCabe, P.J. 1993. Alluvial architecture in a sequence stratigraphy framework: a case history from the Upper Cretaceous of southern Utah, USA. In: Flinth, S. \& Bryant, I.D. (Eds.). The geological Modelling of Hydrocarbon Reservoirs and Outcrops Analogues. Special Publications - International Association of Sedimentologists, 6: 155-168.

Shanley, K.W. \& McCabe, P.J. 1994. Perspectives on the sequence stratigraphy of continental strata. AAPG Bulletin, 78: 544-568.

Tagliari, C.V. 1993. Evolução das sequências mistas (siliciclásticas e carbonáticas) sob a influência da halocinese durante o alboaptiano da plataforma de Regência Bacia do Espírito Santo. Porto Alegre, 159p. Dissertação de Mestrado, Programa de Pós-Graduação em Geociências, Universidade Federal do Rio Grande do Sul.

Tettenhorst, R. \& Moore Jr, G.E. 1978. Stevensite oolites from the Green River Formation of central Utah. Journal of Sedimentary Petrology. 48(2): 587-594.

Vail, P.R., Mitchum, R.M. \& Thompson, S. 1977. Seismic Stratigraphy and Global Changes of Sea Level, part 3: relative changes of sea level from coastal onlap. In: Payton, C.E. (Ed.). Seismic Stratigraphy - applications to hydrocarbon exploration. American Association of Petroleum Geologists Memoir 26. P. 63- 81.

Van Wagoner, J.C., Mitchum, R.M., Champion, K.M. \& Rahmanian, V.D. 1990. Siliciclastic Sequence Stratigraphy in Well Logs, Cores, and Outcrops: Concepts for High Resolution Correlation of Time and Facies. American Association of Petroleum Geologists, Methods in Exploration Series, n. 7, 55p.

Van Wagoner, J.C., Posamentier, H.W., Mitchum, R.M., Vail, P.R., Sarg, J.F., Loutit, T.S. \& Hardenbol, J. 1988. An overview of the fundamentals of sequence stratigraphy. In: Wilgus, C.K, Hastings, B.S., Kendal, C.G.St.C., Posamentier, H.W., Ross, C.A. \& Van Wagoner, J.C. (Eds) SEPM Special Publication 42 - Sea Level Changes: An Integrated Approach, p. 3945

Vieira, R.A.B., Mendes, M.P., Vieira, P.E., Costa, L.A.R., Tagliari, C.V., Bacelar, L.A.P. \& Feijó, F.J. 1994. Bacias do Espírito Santo e Mucuri. Boletim de Geociências da Petrobras, 8(1): 191-202.

Walker, R.G. 1992. Facies, facies models and modern stratigraphic concepts. In: Walker, R.G. \& James, N.P. (Eds). Facies models response to sea level change - Geological Association of Canada, St John's, Newfoundland, 409p.

Wright, P. \& Marriot, S.B. 1993. The sequence stratigraphy of fluvial depositional systems: the role of floodplain sediment storage. Sedimentary Geology, 86(3-4): 203-210. 